\title{
Where should I publish to get promoted? A finance journal ranking based on business school promotions
}

\author{
Emanuele Bajo* \\ Massimiliano Barbi** \\ David Hillier ${ }^{* * *}$
}

This version: February 2020

\begin{abstract}
Hiring and promotion committees consider a broad range of journals and the relative importance of journal titles is highly subjective. In this paper, we present a novel approach to objective Finance journal ranking by considering the impact of journal publications on career advancement. While the top three journals (Journal of Finance, Journal of Financial Economics, Review of Financial Studies) are significant drivers of promotion success, other journals are nearly as important, particularly for business schools outside of the top tier. In rank order, these are the Journal of Banking and Finance, the Journal of Financial and Quantitative Analysis, the Journal of Corporate Finance, and the Review of Finance.
\end{abstract}

JEL Classification: G00.

Keywords: Journal Ranking; Research Assessment; Finance Journals.

* Corresponding Author: University of Bologna, Department of Economics, Piazza Scaravilli 2, 40126 Bologna, Italy. e-mail address: emanuele.bajo@unibo.it.

** University of Bologna, Department of Management.

*** University of Strathclyde, Accounting and Finance Department.

We would like to thank the Editor (Geert Bekaert) and two anonymous Referees, whose suggestions greatly improved the paper. We also thank the participants at the 2019 Financial Engineering and Banking Society (FEBS) conference in Prague and the 2018 European Financial Management Association (EFMA) conference in Milan for their insightful comments and suggestions. Furthermore, we would like to thank Daniela Arzu, Massimiliano Calvia, Donald Campbell, Valentina Febo, and Irene Galletti for their valuable research assistance. All remaining errors or omissions are our own responsibility. A previous version of this paper was circulated as "Where should I publish to get promoted? A finance journal ranking based on promotions among US business schools." 


\section{Introduction}

Research productivity is undoubtedly the main factor driving hiring and promotion decisions in academia. However, evaluating research quality is far from straightforward because of a lack of consensus on an appropriate methodology and quality proxies. Among Finance journals, while general agreement exists regarding the three top-tier journals (the Journal of Finance, the Journal of Financial Economics, and the Review of Financial Studies), below this, the perception of quality varies.

The need for a journal ranking is witnessed by different attempts to assess research quality by national agencies or business school groups. For instance, the UK regularly undertakes a research audit of British universities and allocates institutional funding on the basis of the results. In the same country, the Association of Business Schools (ABS) has a journal ranking for all business subject areas. Similar exercises have been carried out in many other countries (e.g., in Australia and New Zealand with the Journal Quality List developed by the Australian Business Deans Council - ABDC) where national agencies regularly publish journal lists to guide promotion assessments. ${ }^{1}$

At first glance, there is less of a need for a journal ranking in the US. Most top universities are private and do not rely on public funding, which means they are not under the scrutiny of federal agencies in charge of evaluating research quality. The received wisdom is that top business schools hire and promote finance academics based on three top-tier publications (JF, JFE, and RFS). Fishe (1998) studied a sample of newly promoted full professors and found that faculty affiliated with top-20 Finance departments publish, on average, a ratio of 1:3 papers in the three top-tier finance journals. This compares to a 1:6 ratio for professors from lower-ranked departments. Griffiths and Winters (2005) show that professors affiliated with universities outside the top-50 research institutions generally have a very small number of publications in the top three (in some instances, none). It follows that publications at most research universities will embrace a more comprehensive list of publication titles. For specialized papers or those outside of mainstream finance, focusing on

\footnotetext{
1 Recent examples in Europe are the AERES (Agence d'Èvaluation de la Recherche et de l'Enseignement Supérieur) in France and the ANVUR (Agenzia Nazionale di Valutazione del Sistema Universitario e della Ricerca) in Italy.
} 
second-tier journals becomes a necessity and the best possible publishing outcome. Smith (2004) shows that many articles published outside the top-three journals are of similar quality. Applying different criteria for "top articles," type I errors (a "top" article rejected by the topthree journals) and type II errors (a "non-top" article accepted by the top-three journals) are quite common. Smith (2004) concludes that, due to high error rates, the identification of top articles necessitates a consideration beyond JF, JFE, and RFS.

Over the past thirty years, several attempts have been made in the finance literature to offer a ranking of finance journals. Although there is no disagreement on the top-three ranked journals, the relative ranking of other journals varies considerably. For example, the Journal of Financial and Quantitative Analysis (JFQA) and the Journal of Business (JB) have usually occupied the fourth and fifth position (with time-variant ordering), even though in the last decade other journals have been recognized (in particular, the Review of Finance). ${ }^{2}$

In previous research, journal quality has been assessed using three main approaches: surveys, the number of citations, and identifying where top authors publish. Survey methodologies rank journals on the perceived quality of a sample of experts (such as business school deans or finance professors). Citation-based approaches sort titles based on citations received by articles published in each journal. Another methodology takes the fraction of authors published in each journal that belong to a predefined list of top scholars.

Each approach has limitations. Aside from the standard issues of survey-based ranking (such as response and sampling biases), their central flaw derives from perception. Borde, Cheney, and Madura (1999) and Oltheten, Theoharakis, and Travlos (2005) note how quality perception is influenced by familiarity because survey respondents may bias rankings towards their area of expertise. With citation-based studies, even after normalizing raw citation count by the age of the article, the method is in primis influenced by self-citations and strategic citations of important researchers (such as journal editors or likely reviewers). ${ }^{3}$ Also, certain types of article receive more citations (e.g., literature reviews) and the journals that publish these papers tend to rank higher. Another common strategy is to use only references from the

\footnotetext{
${ }^{2}$ The Journal of Business ceased to exist in 2006.

${ }^{3}$ Recently, with the aim to correct for the bias and discourage this practice, the Journal of Citation Report (JCR) has introduced a citation-based measure that excludes self-citations.
} 
top-three journals to give the impression of quality. This form of academic elitism inflates the number of journal citations that are considered aspirational compared to lower quality perceived publications. Using the fraction of top authors to publish in a journal has its own set of challenges. For instance, Chen and Huang (2007) express their concerns about the reliability of metrics (such as the Author Affiliation Index - AAI) to rank journals based on top authors, when a journal has fewer than 40 to 50 articles. Moreover, the identification of top authors depends on a prior and somewhat arbitrary decision regarding which set of journals should be considered (the weakness is similarly present in citation-based studies).

In this paper, we use an alternative approach to assessing journal quality. We construct our ranking by observing which publications are more correlated with the probability of a promotion among faculty affiliated with one of the universities included in the Arizona State Ranking (i.e., institutions showing at least one publication in the top-three finance journals between 2006 and 2015). For each school, we manually download the CVs of each faculty member, we collect the list of publications for each author and build a ranking based on the likelihood of publishing a paper in a given journal in the years around promotion. Our final sample covers 387 schools and 2,910 scholars.

Our approach overcomes some of the drawbacks of other journal ranking methodologies. First, we do not base our ranking on perception, but the actual determinants of academic career progression. Second, unlike earlier research, we do not rely on a preset journal list. The journal titles in our sample are those where finance academics in schools (with at least one academic who has published in a top-three publication in the last ten years) have published their research. Although the vast majority of finance journals in our sample overlaps with the lists offered by previous studies, we also take into consideration titles not previously considered. Third, since we do not directly or indirectly include any metric based on citation count, our approach is free from the biases discussed above.

\section{[Insert Table 1 about here]}


The Finance journal ranking literature is extensive. Coe and Weinstock (1983) surveyed 107 heads of Finance departments on journal quality and found their perception of quality to be uncorrelated with actual journal acceptance rates. Borde, Cheney, and Madura (1999) use a similar approach, surveying 125 department chairs at AACSB accredited business schools, and provide a rank of 55 finance journals. Oltheten, Theoharakis, and Travlos (2005) surveyed 862 finance scholars worldwide to assess five different dimensions of perceived journal quality and document that perceptions of journal ranking vary with geography, research interests, and seniority. Currie and Pandher $(2011,2020)$ surveyed scholars who had published in the last two years in a finance journal covered by the ABS and asked them to rate 102 journals using a 1 (lowest quality) to 5 (highest quality) scale. All of the survey methodology papers ranked JF, JFE and RFS consistently as top-three journals in the discipline.

The first paper that derives a finance journal ranking based on citations is Mabry and Sharplin (1985), where publications are ranked by citations listed in papers published by the JF, JFE, JFQA, and the Journal of Money, Credit and Banking (JMCB). Alexander and Mabry (1994) take a similar approach and report that working papers are the third-largest cited source. More recently, Borokhovich, Lee, and Simkins (2011) use a citation-based approach to showcase JBF and conclude that it is among the most important research outlets and a primary outlet for influential articles in the banking area. Millet-Reyes (2013) considers citations and journal rankings based on the number of articles published with an international finance focus to create an "international score." To address the dynamic nature of changes in citations, Kao, Hsu, Lu, and Fung (2016) use a stochastic dominance (SD) analysis.

Chen and Huang (2007) consider the publication record of top scholars and create an Author Affiliation Index (AAI) to evaluate a journal's prestige. For each journal, the AAI is the fraction of articles authored by scholars affiliated with a predetermined number of top universities. Chan, Chang and Chang (2013) follow a similar approach and, after normalizing citation count by the number of co-authors, compute the journal author concentration index (ACI) by using the proportion of articles authored by a predetermined number of top finance researchers. The main difference between AAI and ACI is the base for the ranking: while AAI considers the university rank, the ACI is based on a rank of scholars, regardless of their affiliation with a top business school. Danielson and Heck (2014) examine the publications of prolific authors and present evidence that prolific finance authors route their research towards 
four top-tier journals (JF, JFE, RFS, and JFQA). Crook and Walrup (2016) reach a similar conclusion and argue that (excluding the top journals) niche finance outlets rank higher than generalist journals.

Outside these three main approaches, few other attempts have been made to create a journal ranking. Beattie and Goodacre (2006) propose a journal ranking using the 2001 research exercise in the UK (RAE, now called REF). Brown (2003) ranks 18 accounting and finance journals using the number and percentage frequency of Social Science Research Network (SSRN) downloads of articles published in a given journal. Reinartz and Urban (2017) consider the impact of presenting a paper in specific conferences on subsequent publication quality and report a positive relationship. Although not directly linked, there will necessarily be an indirect relationship between specific conference presentation and promotion outcomes through the journal acceptance. Netter, Poulsen, and Kieser (2018) report that promotions to associate professor are associated with an average number of top tier publications close to 3 (out of 6 to 8 overall publications). Promoted assistant professors from top schools are slightly more prolific in terms of top journals. However, the promotion-to-associate figures for current full professors at these institutions are in line with those of University of Georgia's peers.

In this paper, we present evidence that assistant professors have only 20.5 per cent of their outputs in a top-three journal, followed by 17.4 per cent and 18.4 per cent for associate and full professors, respectively. While the top-three journals (Journal of Finance, Journal of Financial Economics, Review of Financial Studies) are strongly correlated with promotion success, over 80 per cent of an academic's publication profile will normally consist of other journal publications. Our results suggest the following journals to be particularly influential: Journal of Banking and Finance, Journal of Financial and Quantitative Analysis, Journal of Corporate Finance, and Review of Finance.

The rest of the paper is structured as follows. In section 2, we present our data. Section 3 contains our core tests to create a final journal ranking based on promotion data, and section 4 concludes. 


\section{Data collection and methodology}

We draw our data from three different sources. First, the ranking provided by Arizona State University is used to identify the universities that have at least one member who has published a paper in the time window between 2006 to 2015 in one of the following top finance journals: Journal of Finance, Journal of Financial Economics, Review of Financial Studies. ${ }^{4}$ Using a 10-year sample period allows us to cover active scholars. We believe that setting a threshold to at least one top-tier publication in a ten-year window allows us to select a panel of schools with comparable hiring and promotion practices, despite the geographical origin. This procedure leads to 387 institutions in the sample, 194 of which are located in the US and 193 elsewhere.

\section{[Insert Table 2 about here]}

Table 2 reports the full breakdown of institutions by country. US and non-US schools have an equal weighting in the sample with US business schools comprising 50.1 per cent of the sample. Business schools from the UK, France, Italy, Germany, Switzerland and Spain (in this order) account for approximately 20 per cent of the institutions in our sample. Asian universities, although increasing in number over recent years, lag behind, with China, South Korea and Hong Kong contributing most in terms of numbers on the list.

For the 387 institutions in the sample, we manually collect information on all finance department staff (or economics and accounting, in the case of aggregated departments) from the university website. We restrict our sample to assistant, associate and full professors. Visiting and adjunct professors, executive (and clinical) professors, professors on leave and lecturers were excluded from the sample. For each staff member, we collect relevant available sociodemographic characteristics (such as gender type and education) from their university resume. ${ }^{5}$

\footnotetext{
${ }^{4}$ The list is available at: $\mathrm{http}: / /$ apps.wpcarey.asu.edu/fin-rankings/rankings/results.cfm.

${ }^{5}$ We retrieve this public information from the institutional or personal webpage of each faculty member. We also use public LinkedIn profiles to double check the accuracy of some information.
} 
In particular, we collect information on the $\mathrm{PhD}$-granting institution, the $\mathrm{PhD}$ completion year and the $\mathrm{PhD}$ field (finance, economics, or other). Employment history was traced backwards, from the current position held to the first position immediately following $\mathrm{PhD}$ completion date, including length of time at the employer university.

The third source of information is the Scopus database. After manually matching each faculty member with the Scopus identification number, we obtain the list of all publications. For each record, we trace the journal in which each article is published and the publication year. The final dataset includes career advancements of faculty members and their track record of publications in each finance journal in the five years around promotion (from -4 to +1 relative to the promotion year). The final dataset comprises information on 2,910 finance scholars. Table 2 presents a breakdown of academic by nationality, for which information is available (1,979 out of 2,910 scholars had no nationality data).

Like other studies, our approach has some weaknesses. First, although we carefully search for a finance-related department in each university, it is plausible that some finance scholars are not detected. This could happen in small schools where finance researchers are affiliated with a department broader in scope (for instance, management). Also, not all schools provide a very detailed list of their faculty members. Although this is less likely to occur in larger and more established universities, smaller schools may be less diligent in providing accessible information on their finance faculty. Finally, while some universities require their affiliates to publish detailed information on their professional expertise and achievements (mostly in a standardized form), some institutions may leave the decision to each scholar. Thus, our identification strategy cannot guarantee a full coverage of finance scholars at the universities in our sample.

It is unlikely this will bias our results because poor staff information quality tends to occur in smaller and less research-oriented universities, or for scholars who deliberately prefer not to disclose their information online. In the former case, given the size of the institution, we expect the number of faculty members involved is minimal. In the latter case, it is likely to be associated with close-to-retirement or inactive scholars, for which the number of publications is expected to be irrelevant. 


\section{[Insert Table 3 about here]}

\section{Finance journal ranking}

Table 3 reports some descriptive statistics. Full professors comprise 42 per cent of the whole sample. The rest of the sample is almost equally split between assistant and associate professors. Table 3 also presents the nationality, the area of the $\mathrm{PhD}$ and gender mix. In total, 63 per cent of faculty members is American (but nationality is explicitly mentioned in only 931 resumes out of 2,910). Apart from a small fraction of cases (13 per cent), 60 per cent of the sample had a $\mathrm{PhD}$ in finance and 27 per cent a $\mathrm{PhD}$ in economics. Finally, the sample of finance scholars is highly skewed towards males with only 18 per cent of the sample consisting of female academics.

\section{[Insert Table 4 about here]}

Table 4 shows, for each of the three academic ranks, information on research productivity. As of December 2017, assistant professors are on average (median) 6.0 (5.0) years from the year of their degree. The relatively young age is no surprise, as this position is generally tenure-track and thus held for a limited number of years. The table also reports the number of publications, broken down between top-tier (JF, JFE, and RFS) and other finance journals. Assistant professors show an average of 3.9 articles, 0.8 (20.5 per cent) of which are published in a top-three journal. Moving to associate and full professors, the distance from the $\mathrm{PhD}$ year increases to 13 and 24 years, respectively, in line with the number of publications. Associate professors have an average (median) of 9.2 (8) published articles, and full professors have almost three times as much with 23.4 (19) publications. In these two distinct cases, the number of top-tier publications is on average 1.6 (out of 9.2, 17.4 per cent) and 4.3 (out of 23.4, 18.4 per cent) for associate and full professor, respectively. Interestingly, over the whole sample and regardless of the academic rank, scholars roughly show one top-tier out of five publications, which is a figure lower than that reported by Fishe (1998), which was one out of three. 


\section{[Insert Table 5 about here]}

Table 5 reports the number and percentage of promotions in our sample from 1990 to 2016. ${ }^{6}$ Over the 2,054 promotions, 1,133 (55 per cent) relate to the most recent decade. While in the first ten years of our sample period we record approximately 35 promotions per year, in the last decade the same figure is more than tripled. This difference is only partially due to increased hiring activity, as it also reflects the effect of retirements. A large percentage of academics promoted in the 90s (especially to full professor level) might have ceased working and are no longer listed on the university website, which means they will not be detected by our data collection. This effect is also evident if we contrast the number of promotions to the number of scholars present in our dataset for every given year. ${ }^{7}$ The ratio between these two figures is the promotion rate, which is fairly constant through the entire sample period and close to 5 per cent per year per academic.

\section{[Insert Table 6 about here]}

Table 6 presents the journals sorted by frequency of appearance, regardless of the rank of the business school, or association with career progression. Since we can assume that the propensity to publish in a given journal is mainly driven by the requirements imposed by the employer, this ranking can be interpreted as a first journal ranking based on academic promotions. The ordering is affected by the total number of articles published, as well as the time coverage, which varies from journal to journal. As expected, the first three positions are

\footnotetext{
${ }^{6}$ We do not consider year 2017 as we correlate publications in the five years around promotion to career advancement (therefore, 2017 publications are used for the $[-4,+1]$ time window associated to 2016 promotions).

${ }^{7}$ We manually collected scholars' CVs during the period 2018-2019. Therefore, the sample of scholars in our sample at the beginning of the period (1990) is only made of professors who had been already hired then and still in the faculty list at the present times. The scholars active at the beginning of the sample period and no longer present in the university web sites, mostly due to the effect of retirement, cannot be traced using this search method.
} 
occupied by the Journal of Financial Economics, the Journal of Finance, and the Review of Financial Studies. The first two journals show a similar number of hits: in our sample, scholars have published 2,857, 2,603, and 1,846 times in JFE, JF, and RFS, respectively. Just below the first-tier are the Journal of Banking and Finance (1,595 articles) and the Journal of Financial and Quantitative Analysis (1,219 articles).

The Journal of Business and the Review of Finance, which are often ranked among to the next to top-tier journals, are not in the high end of this ranking, as they appear $30^{\text {th }}$ (with 259 articles) and $14^{\text {th }}$ (with 382 articles), respectively. However, while the former ceased to exist in 2006, the latter has started operating quite recently (since 2004, and was previously known as the European Finance Review, since 1997). Between the sixth and tenth position, the list reports two journals classified by the Association of Business School (ABS) ranking as Economics journals, i.e. the American Economic Review and the Journal of Monetary Economics; one (Management Science) whose scientific scope is open to all topics in management, finance and economics; and two finance publications: the Journal of Corporate Finance and the Financial Analysts Journal.

\section{[Insert Table 7 about here]}

Table 7 is the first attempt to build a journal ranking based on the association between promotion and publication in a given journal. For each observed advancement in career (from assistant to associate, or from associate to full professor), we trace the number of publications in each journal in a period ranging from 4 years before to 1 year after the promotion year. The reason for not limiting our attention to the single year of the promotion is based on the assessment of research output that promotion committees usually put in place. The decision to promote a candidate is likely to be a function of the portfolio of publications produced in recent years as well as current works that reasonably will soon be published (i.e., revise and resubmit at late rounds). Although the time window around the promotion year may appear arbitrary, by slightly altering the window period, for instance considering $[-3,+1]$ and $[-5,+1]$, we obtain similar results. Similarly, we adjust for co-authorship through dividing the number of 
publications in any given journal by the number of co-authors. None of the rankings presented in this paper is significantly affected. ${ }^{8}$

To account for time changes in the perceived importance of these journals, we split our 27-year sample period into three sub-periods of equal length: from 1990 to 1998, from 1999 to 2007 and from 2008 to 2016. For each sub-period, we report the number of publications detected in the window $[-4,+1]$ year around the promotion, the average number of publications (i.e., the ratio between the number of publications and the number of promotions), and the rank based on the frequency of appearance within the list. Splitting the period allows us also to avoid any possible bias induced by journals that do not exist over the whole period. For instance, the Journal of Business ceased its activity in 2006, and a few highly ranked journals began publishing in the 90 s. $^{9}$

Starting with the most recent sub-period, unsurprisingly and consistent with prior evidence, JFE (563), RFS (505) and JF (388) dominate the list by number of publications. The same picture, in relative terms, shows that each promoted faculty member had on average about 0.56 JFE, 0.51 RFS, and 0.39 JF. To ease interpretation of these figures, consider RFS as an example. During the 2008-2016 period, approximately one in every two promoted academics had published a paper at RFS in the four years preceding the promotion or the year immediately after. If we then cumulate the number of RFS publications (505 articles) among the promoted sample (997 instances, unreported), this is roughly equal to half of the promoted faculty. The same interpretation applies to JFE (the number of JFE publications is 0.56 times the number of promoted faculty), to JF (the number of JFE publications is 0.39 times the number of promoted faculty) and to any other journal.

Further down the list, promoted professors tend to publish at the JBF (0.25 per promotion), JFQA (0.20 per promotion), JCF (0.17 per promotion) and RF (0.08 per promotion). Although there is a sizeable difference from third to fourth journal rank, as we descend the ranking the distance becomes progressively smaller. This evidence suggests that

\footnotetext{
${ }^{8}$ The ranking adjusted for co-authorship is unreported in the paper but is available upon request.

${ }^{9}$ They are: the Review of Finance (since 2004, previously known as the European Finance Review, since 1997), the Journal of Financial Markets (since 1998), the Journal of Corporate Finance (since 1994), the Journal of Empirical Finance (since 1993), the Review of Quantitative Finance and Accounting (since 1991), and the Journal of Derivatives (since 1993).
} 
other journals such as FM, JFMKT, the Journal of Empirical Finance (JEF), the Journal of International Money and Finance (JIMF), European Financial Management (EFM), and JFI are barely distinguishable from each other and probably not too distant from seventh position (RF).

Moving to the previous period (1999-2007), while the first five positions remain unchanged, some interesting insights emerge. Apart from the sixth position of JB, most secondtier journals (FM and JCF) have a similar performance. Other journals, such as JFM, JFR or FAJ, are ranked higher than in the 2008-2016 subperiod, probably due to a lower perceived prestige among scholars and promotion committees. The earliest period (1990-1998) has an entirely different ranking, and RFS is only $9^{\text {th }}$ due to its relatively young age. Among the top ten journals, we observe a few outlets that nowadays are less frequently included among the second-tier journals, such as the Journal of Financial Research and the Financial Review, fourth and fifth respectively.

\section{[Insert Table 8 about here]}

Different approaches to determine journal ranking are likely to produce a different journal quality sorting. To gauge how the ranking based on promotion activities is different from other studies, Table 8 contrasts the journal ranking shown in the previous Table 7 (20082016 period) with Currie and Pandher $(2011,2020)$ and Chan, Chang, and Chang (2013), based on survey and top-scholar approach, respectively. ${ }^{10}$ If the top-tree journals are unquestionably in the top-end of the rankings, although with different order, this table evidences an uneven presence of the other journals among the second-tier. First, among the second-ranked journals, JFQA is quite consistently considered a top journal, ranking between the fourth and the fifth position, followed according to Currie and Pandher (2011) and our ranking (but not in Chan et al., 2013) by JBF. Instead, Currie and Pandher (2020) place RF just one notch below JFQA and before JBF. The quality of JCF is comparable to that of JBF according to Currie and Pandher (2020), and very close also considering our ranking. The journals FM, JFMKT and EFM follow

\footnotetext{
${ }^{10}$ Chan et al. (2013) offer three methods to determine the journal ranking. In this table we report the ranking obtained as the average of the three methods.
} 
behind across all three rankings, while JFI, which is only $13^{\text {th }}$ in terms of correlation with promotion success, ranks between JFQA and JBF in Chan et al. (2013), and is comparable to JBF in the other two rankings.

\section{[Insert Table 9 about here]}

A possible caveat is that not all journals publish the same number of articles every year. As a result, promotions could be associated with more articles in a given journal, not because this is required or valued by the employer, but because of the number of journal articles in each issue is large. If not appropriately scaled, our journal rank would unfairly reward prolific journals with a broader topic spectrum at the expense of titles with a narrower scope and a limited number of annual issues. Table 9 presents the same journal rank for the three subperiods, where the number of articles is scaled by the total number of articles published by each journal in the same period. To ease interpretation, the first journal in this rank is RFS with 41.5 per cent which suggests that promoted professors have published 41.5 per cent of the total articles published in the RFS in the considered time period. To reflect this figure to the reported numbers, we know that in the time window 2008-2016 the 997 promoted academics have cumulatively published 505 papers in the RFS. In the time period between 2004 (four years before 2008) and 2017 (one year after 2008), RFS published 1,218 papers. By scaling the 505 papers over the total number of publications we obtain the reported 41.5 per cent. It is intuitively clear that the higher the percentage, the stronger the association of the journal with promotion success. Since the percentages in Table 9 are relative, we address any potential inflation effect generated by an editorial policy to increase the number of annual issues or article count.

The results in Table 9 confirm the importance of the top four journals, with a slight difference in order among the top three. Further down, JFMKT and JFI increase their ranks, and they are in the fifth and ninth position respectively, against the ninth and thirteenth positions shown in the unscaled ranking. This upward movement in rank is to be expected since both journals have a narrower topic scope as compared to other more mainstream outlets. 


\section{[Insert Table 10 about here]}

It may be that the performance of non-top-tier journals is weaker than merited because more prestigious universities only consider JF, JFE or RFS in promotion applications. As a consequence, promotions in these schools are unlikely to be associated with publications outside of top journals and faculty hired by these universities seldom list in their CVs articles published in non-top-tier journals. To account for this, Table 10 reports the same analysis broken down in three groups based on institution ranking. ${ }^{11}$ Quite unsurprisingly, the publications tend to cluster around the top-three journals and the average number of publications per promoted faculty in these outlets sharply increases. For instance, the average number of JF papers goes, from a 0.39 for the whole sample, to 1.13 , which is almost three times larger.

Moving from higher to lower ranked institution groups, the number of top-tier publications sharply decreases and so does the ratio between top to second (or third) tier outlets. This evidence is consistent with Fishe (1998) and confirms the interest of having a journal ranking outside of the usual three dominant outlets. If we focus our attention on the second or third groups, we can document two central insights. First, some journals, such as JBF and JCF, are (almost) as common among promoted faculty as those of more prestigious outlets. In particular, in the third group of 275 schools, JBF ranks first and outranks the top-tier journals in terms of appearances. Second, the same set of journals (RF, JFI, and FM) are in the top-15 list regardless of institution quintile.

\section{[Insert Table 11 about here]}

In the last set of analyses, we contrast the rankings by geographically splitting the sample between North America (US and Canada), Europe and the rest of world taking into

\footnotetext{
${ }^{11}$ Groups are constituted as follows: the first 25 schools in the Arizona State University ranking (more than 55 articles in the top-three finance journals between 2006 and 2015) are classified as "group 1," the following 87 schools (between 10 and 54 articles in the top-three finance journals) are classified as "group 2," while the remaining 275 schools are classified as "group 3."
} 
consideration the whole period (1990-2016). ${ }^{12}$ Table 11 presents our results. While the total number of publications is not informative because we are comparing three numerically unbalanced sub-samples, some patterns come from the number of articles per promotion and, more importantly, differences in the rankings of individual journals.

The first insight shows that promoted North America-based scholars published more articles in the three top-tier journals compared to those working in non-US and Canadian schools. North America-based professors are associated with almost twice as many articles in JF, JFE, and RFS. This disparity is because of the different average rank between US and nonUS schools, more than any difference in recruitment or promotion policies. The first ten positions belong to US universities and, among the top twenty-five, only LBS, LSE, and the Swiss Finance Institute are from outside the US.

The second insight concerns the different journal rankings. In the North-America ranking, JBF takes the fifth position with 0.16 articles per promotion, not too far from 0.24 articles in the JFQA, and right before JCF ( 0.11 articles per promotion). If we look at other regions, while JCF is consistently sixth, JBF takes the top position in Europe ( 0.34 articles per promotion) and the second rank in the rest of the world. Interestingly, we also document a local home bias in the ranking. For instance, European Financial Management, absent in the NorthAmerican top-20 finance journals, ranks ninth in the European ranking and Pacific-Basin Finance Journal is seventh in rest of the world ranking, clearly driven by its popularity in the Asian and Australian regions.

\section{Conclusions}

Research productivity is the main driver for appointment and promotion decisions among Finance academics. However, while the Journal of Finance, the Journal of Financial Economics, and the Review of Financial Studies, are undoubtedly regarded as top-tier publications, more uncertainty exists when ranking other internationally regarded Finance

\footnotetext{
${ }^{12}$ Rest of the world includes schools based in Asia, Australia/Oceania, South and Central America and Mexico.
} 
journals. An objective journal ranking is important in countries where promotions and institutional research funding formulae are tied to research publications. In the US, even in the absence of a national research exercise, the number of publications outside the top-three journals is large among top finance departments, which makes a ranking of finance journals relevant to hiring and promotion committees in all academic environments.

In this paper, we propose a new methodology to rank finance journals based on the career advancement of scholars in relation to publication success in each title. Unsurprisingly, the top-tier journals dominate the list when looking at the publication record of promoted scholars within a 6-year window around the promotion date. We document that in the most recent period (from 2008 to 2016), promoted professors have regularly published in the Journal of Banking and Finance, Journal of Financial and Quantitative Analysis, Journal of Corporate Finance, and Review of Finance, in this order. If we scale the number of publications by number of articles published in each journal, the Journal of Financial Markets and the Journal of Financial Intermediation are equally important to promotion decisions. Disaggregating our analysis by business school reputation or geography, if we exclude the top- 25 in the university ranking (mostly located in the US), we find that some journals, such as the Journal of Banking and Finance and the Journal of Corporate Finance are regular publications among promoted faculty, and their frequency is virtually the same, if not more, than more prestigious journals. Regardless of the business school, other journals, such as the Journal of Financial Markets, Financial Management, the Financial Analysts Journal, and the Journal of Financial Intermediation are hardly distinguishable from each other and not too distant from the fifth position.

The journal ranking presented in this paper can be used by finance researchers as a guide to inform where they should target their research papers. While the top three journals (JF, JFE, and RFS) are undoubtedly significant drivers for promotion success, careful selection of a target journal (especially RF, JFQA, JBF and JCF) outside this list can enhance promotion prospects. Specialist journals (such as JFI, JFMKT, and FAJ) are also strong contributors. 


\section{References}

Alexander, J.C. and R.H. Mabry, 1994, Relative significance of journals, authors, and articles cited in financial research, Journal of Finance 49(2), 697-712.

Beattie, V. and A. Goodacre, 2006, A new method for ranking academic journals in accounting and finance, Accounting and Business Research 36(2), 65-91.

Borde, S.F., Cheney, J.M., and J. Madura, 1999, A note on perceptions of finance journal quality, Review of Quantitative Finance and Accounting 12(1), 89-96.

Borokhovich, K.A., Lee, A.A. and B.J. Simkins, 2011, A framework for journal assessment: The case of the Journal of Banking \& Finance, Journal of Banking and Finance 35(1), 16.

Brown, L.D., 2003, Ranking journals using Social Science Research Network downloads, Review of Quantitative Finance and Accounting 20(3), 291-307.

Chan, K.C., Chang, C.H., and Y. Chang, 2013, Ranking of finance journals: Some Google Scholar citation perspectives, Journal of Empirical Finance 21, 241-250.

Chen, C.R. and Huang, Y., 2007, Author Affiliation Index, finance journal ranking, and the pattern of authorship, Journal of Corporate Finance 13(5), 1008-1026.

Coe, R.K. and I. Weinstock, 1983, Evaluating the finance journals: the department chairperson's perspective, Journal of Financial Research 6(4), 345-349.

Crook, M.D. and B.R. Walrup, 2016, Rankings and trends in finance publishing: An iterative approach, Journal of Financial Research 39(3), 291-322.

Currie, R.R. and G.S. Pandher, 2011, Finance journal rankings and tiers: An Active Scholar Assessment methodology, Journal of Banking and Finance 35(1), 7-20.

Currie, R.R. and G.S. Pandher, 2020, Finance journal rankings: Active scholar assessment revisited, Journal of Banking and Finance 111, 105717.

Danielson, M. and J. Heck, 2014, Voting with their feet: In which journals do the most prolific finance researchers publish?, Financial Management 43(1), 1-27.

Danielson, M. and J. Heck, 2016, A research portfolio approach to evaluating finance journal quality, Managerial Finance 42(4), 338-353.

Fishe, R.P.H., 1998, What are the research standards for full professor of finance?, Journal of Finance 53(3), 1053-1079.

Griffiths, M.D. and D.B. Winters, 2005, Inferring promotion and tenure research hurdles: What the data say, Journal of Financial Education 31, 1-25. 
Kao, E.H., Hsu, C.-H., Lu, Y., and H. Fung, 2016, Ranking of finance journals: a stochastic dominance analysis, Managerial Finance 42 (4), 312-323.

Mabry, R.H. and A.D. Sharplin, 1985, The relative importance of journals used in finance research. Journal of Financial Research 8(4), 287-296.

Millet-Reyes B., 2013, The impact of citations in International Finance, Global Finance Journal 24(2), 129-139.

Netter, J.M., A.B. Poulsen, and W.P. Kieser, 2018, What does it take? Comparison of research standards for promotion in finance, Journal of Corporate Finance 49, 379-387.

Oltheten, E., Theoharakis, V., and N.G. Travlos, 2005, Faculty perceptions and readership patterns of finance journals: A global view, Journal of Financial and Quantitative Analysis 40(1), 223-239.

Reinartz, S and D. Urban (2017), Finance conference quality and publication success: A conference ranking, Journal of Empirical Finance 42, 155-174.

Smith, S., 2004, Is an article in a top journal a top article?, Financial Management 33(4), 133149. 


\begin{tabular}{|c|c|c|c|}
\hline Paper & Approach & No. of journals & Period \\
\hline Alexander and Mabry (1994) & Citations & 50 & 1987-1991 \\
\hline Beattie and Goodacre (2006) & Other & 408 & $1996-2000$ \\
\hline Borde, Cheney, and Madura (1999) & Survey & 55 & NA \\
\hline Borokhovich, Lee, and Simkins (2011) & Citations & 12 & 2008-2009 \\
\hline Brown (2003) & Other & 18 & 2001 \\
\hline Chan, Chang, and Chang (2013) & Top Scholars & 23 & $1990-2010$ \\
\hline Chen and Huang (2007) & Top Scholars & 41 & NA \\
\hline Coe and Weinstock (1983) & Survey & 20 & NA \\
\hline Crook and Walrup (2016) & Top Scholars & 20 & 1985-2014 \\
\hline Currie and Pandher (2011) & Survey & 83 & NA \\
\hline Currie and Pandher (2020) & Survey & 102 & NA \\
\hline Danielson and Heck (2014) & Top Scholars & 23 & 1970-2009 \\
\hline Danielson and Heck (2016) & Top Scholars & 23 & $1970-2014$ \\
\hline Kao, Hsu, Lu, and Fung (2016) & Citations & 23 & $1990-2010$ \\
\hline Mabry and Sharplin (1985) & Citations & 30 & 1980-1985 \\
\hline Millet-Reyes (2013) & Citations & 31 & $2007-2008$ \\
\hline Netter, Poulsen, and Kieser (2018) & Other & NA & NA \\
\hline Oltheten, Theoharakis, and Travlos (2005) & Survey & 40 & NA \\
\hline
\end{tabular}

Table 1 - Main studies on finance journal rankings. The table reports the main studies conducted to rank the top finance journals. The table also shows the approach used by the authors to establish the ranking, the number of finance journals considered, and the period analysed. 


\begin{tabular}{|c|c|c|c|c|c|c|}
\hline \multirow[b]{2}{*}{ Country } & \multicolumn{3}{|c|}{ Schools } & \multicolumn{3}{|c|}{ Scholars } \\
\hline & $\mathbf{N}$ & Percent & Cumulative & $\mathbf{N}$ & Percent & Cumulative \\
\hline$U S A$ & 194 & 50.1 & 50.1 & 587 & 63.1 & 63.1 \\
\hline$U K$ & 27 & 7.0 & 57.1 & 7 & 0.8 & 63.8 \\
\hline Canada & 21 & 5.4 & 62.5 & 13 & 1.4 & 65.2 \\
\hline France & 14 & 3.6 & 66.1 & 17 & 1.8 & 67.0 \\
\hline Italy & 11 & 2.8 & 69.0 & 96 & 10.3 & 77.3 \\
\hline Germany & 10 & 2.6 & 71.6 & 27 & 2.9 & 80.2 \\
\hline China & 9 & 2.3 & 73.9 & 31 & 3.3 & 83.6 \\
\hline Australia & 8 & 2.1 & 76.0 & 1 & 0.1 & 83.7 \\
\hline Switzerland & 8 & 2.1 & 78.0 & 8 & 0.9 & 84.5 \\
\hline Spain & 7 & 1.8 & 79.8 & 14 & 1.5 & 86.0 \\
\hline Netherlands & 6 & 1.6 & 81.4 & 9 & 1.0 & 87.0 \\
\hline South Korea & 6 & 1.6 & 82.9 & 14 & 1.5 & 88.5 \\
\hline Hong Kong & 5 & 1.3 & 84.2 & 0 & 0.0 & 88.5 \\
\hline Portugal & 5 & 1.3 & 85.5 & 4 & 0.4 & 88.9 \\
\hline Israel & 4 & 1.0 & 86.6 & 0 & 0.0 & 88.9 \\
\hline Japan & 4 & 1.0 & 87.6 & 14 & 1.5 & 90.4 \\
\hline Norway & 4 & 1.0 & 88.6 & 3 & 0.3 & 90.8 \\
\hline Austria & 3 & 0.8 & 89.4 & 4 & 0.4 & 91.2 \\
\hline Belgium & 3 & 0.8 & 90.2 & 2 & 0.2 & 91.4 \\
\hline Denmark & 3 & 0.8 & 91.0 & 14 & 1.5 & 92.9 \\
\hline India & 3 & 0.8 & 91.7 & 9 & 1.0 & 93.9 \\
\hline Singapore & 3 & 0.8 & 92.5 & 3 & 0.3 & 94.2 \\
\hline Sweden & 3 & 0.8 & 93.3 & 5 & 0.5 & 94.7 \\
\hline United Arab Emirates & 3 & 0.8 & 94.1 & 0 & 0.0 & 94.7 \\
\hline Chile & 2 & 0.5 & 94.6 & 4 & 0.4 & 95.2 \\
\hline Finland & 2 & 0.5 & 95.1 & 1 & 0.1 & 95.3 \\
\hline Ireland & 2 & 0.5 & 95.6 & 1 & 0.1 & 95.4 \\
\hline New Zealand & 2 & 0.5 & 96.1 & 0 & 0.0 & 95.4 \\
\hline Taiwan & 2 & 0.5 & 96.6 & 0 & 0.0 & 95.4 \\
\hline Turkey & 2 & 0.5 & 97.2 & 5 & 0.5 & 95.9 \\
\hline Argentina & 1 & 0.3 & 97.4 & 1 & 0.1 & 96.0 \\
\hline Brazil & 1 & 0.3 & 97.7 & 6 & 0.6 & 96.7 \\
\hline Bulgaria & 1 & 0.3 & 97.9 & 2 & 0.2 & 96.9 \\
\hline Cyprus & 1 & 0.3 & 98.2 & 1 & 0.1 & 97.0 \\
\hline Greece & 1 & 0.3 & 98.4 & 6 & 0.6 & 97.6 \\
\hline Hungary & 1 & 0.3 & 98.7 & 2 & 0.2 & 97.9 \\
\hline Iceland & 1 & 0.3 & 99.0 & 0 & 0.0 & 97.9 \\
\hline Luxembourg & 1 & 0.3 & 99.2 & 1 & 0.1 & 98.0 \\
\hline Mexico & 1 & 0.3 & 99.5 & 0 & 0.0 & 98.0 \\
\hline Puerto Rico & 1 & 0.3 & 99.7 & 0 & 0.0 & 98.0 \\
\hline Russia & 1 & 0.3 & 100.0 & 5 & 0.5 & 98.5 \\
\hline Colombia & 0 & 0.0 & 100.0 & 2 & 0.2 & 98.7 \\
\hline Czech Republic & 0 & 0.0 & 100.0 & 1 & 0.1 & 98.8 \\
\hline Malaysia & 0 & 0.0 & 100.0 & 1 & 0.1 & 98.9 \\
\hline Poland & 0 & 0.0 & 100.0 & 2 & 0.2 & 99.1 \\
\hline Romania & 0 & 0.0 & 100.0 & 1 & 0.1 & 99.2 \\
\hline Slovak Republic & 0 & 0.0 & 100.0 & 2 & 0.2 & 99.5 \\
\hline Thailand & 0 & 0.0 & 100.0 & 2 & 0.2 & 99.7 \\
\hline Tunisia & 0 & 0.0 & 100.0 & 1 & 0.1 & 99.8 \\
\hline Ukraine & 0 & 0.0 & 100.0 & 1 & 0.1 & 99.9 \\
\hline Uruguay & 0 & 0.0 & 100.0 & 1 & 0.1 & 100.0 \\
\hline Total & 387 & 100.0 & & 931 & 100.0 & \\
\hline
\end{tabular}

Table 2 - Number of institutions and scholars by country. The table reports the number of institutions and scholars by country of origin for the sample of 2,910 scholars, as of December 31, 2017. 


\begin{tabular}{lccc}
\hline \hline & $\mathbf{N}$ & $\mathbf{N}, \boldsymbol{\%}$ \\
\cline { 3 - 3 } \cline { 3 - 3 } Assistant professors & 757 & 26.0 \\
Associate professors & 924 & 31.8 \\
Full professors & 1,229 & 42.2 \\
$\quad$ Total scholars & 2,910 & 100.0 \\
$\quad$ Total schools & 387 & \\
Nationality & & \\
$\quad$ US & 587 & 63.1 \\
$\quad$ Non-US & 344 & 36.9 \\
$\quad$ Not explicitly indicated & 1,979 & \\
PhD area & & \\
$\quad$ Finance & 1,673 & 60.0 \\
$\quad$ Economics & 740 & 26.5 \\
$\quad$ Other & 375 & 13.5 \\
$\quad$ Not explicitly mentioned & 122 & \\
Gender & & \\
$\quad$ Male & & \\
$\quad$ Female & 2,387 & 18.0 \\
\hline \hline
\end{tabular}

Table 3 - Sample characteristics. The table reports the characteristics of the sample of 2,910 scholars as of December 31, 2017, i.e. their academic rank (assistant professor, associate professor, full professor), their nationality (US $v s$. non-US), their $\mathrm{PhD}$ area (Finance, Economics, Other), and their gender. 


\begin{tabular}{|c|c|c|c|c|c|c|c|}
\hline & Mean & SD & Min & Q1 & Median & Q3 & $\operatorname{Max}$ \\
\hline \multicolumn{8}{|l|}{ Assistant professors, $\mathrm{N}=757$} \\
\hline Years from $P h D$ & 6.0 & 4.3 & 0.0 & 3.0 & 5.0 & 8.0 & 31.0 \\
\hline No. publications & 3.9 & 4.0 & 1.0 & 1.0 & 2.0 & 5.0 & 36.0 \\
\hline No. top-tier publications & 0.8 & 1.3 & 0.0 & 0.0 & 0.0 & 1.0 & 11.0 \\
\hline No. non-top-tier publications & 3.1 & 4.0 & 0.0 & 1.0 & 2.0 & 4.0 & 36.0 \\
\hline \multicolumn{8}{|l|}{ Associate professors, $\mathrm{N}=924$} \\
\hline Years from $P h D$ & 13.4 & 7.2 & 0.0 & 8.5 & 12.0 & 17.0 & 48.0 \\
\hline No. publications & 9.2 & 7.1 & 1.0 & 5.0 & 8.0 & 12.0 & 57.0 \\
\hline No. top-tier publications & 1.6 & 2.2 & 0.0 & 0.0 & 1.0 & 3.0 & 12.0 \\
\hline No. non-top-tier publications & 7.6 & 7.1 & 0.0 & 3.0 & 6.0 & 10.0 & 57.0 \\
\hline \multicolumn{8}{|l|}{ Full professors, $\mathrm{N}=1229$} \\
\hline Years from $P h D$ & 23.9 & 9.9 & 0.0 & 17.0 & 22.0 & 31.0 & 68.0 \\
\hline No. publications & 23.4 & 20.7 & 1.0 & 11.0 & 19.0 & 29.0 & 248.0 \\
\hline No. top-tier publications & 4.3 & 6.9 & 0.0 & 0.0 & 2.0 & 6.0 & 70.0 \\
\hline No. non-top-tier publications & 19.1 & 19.4 & 0.0 & 8.0 & 14.0 & 25.0 & 247.0 \\
\hline
\end{tabular}

Table 4 - Record of publications by academic rank. The table reports the number of publications of 2,910 scholars, divided into top-tier publications (i.e., articles published in the top-three finance journals: JF, JFE, and RFS) $v s$. nontop-tier publications, by academic rank (i.e., assistant professor, associate professor, and full professor), as of December 31, 2017. 


\begin{tabular}{|c|c|c|c|c|c|}
\hline Year & No. of promotions & Percent & Cumulative & No. of scholars & Promotion ratio \\
\hline 1990 & 32 & 1.6 & 1.6 & 502 & 6.4 \\
\hline 1991 & 26 & 1.3 & 2.8 & 537 & 4.8 \\
\hline 1992 & 46 & 2.2 & 5.1 & 590 & 7.8 \\
\hline 1993 & 25 & 1.2 & 6.3 & 643 & 3.9 \\
\hline 1994 & 43 & 2.1 & 8.4 & 712 & 6.0 \\
\hline 1995 & 33 & 1.6 & 10.0 & 780 & 4.2 \\
\hline 1996 & 48 & 2.3 & 12.3 & 843 & 5.7 \\
\hline 1997 & 42 & 2.0 & 14.4 & 903 & 4.7 \\
\hline 1998 & 62 & 3.0 & 17.4 & 992 & 6.3 \\
\hline 1999 & 44 & 2.1 & 19.5 & 1,080 & 4.1 \\
\hline 2000 & 62 & 3.0 & 22.5 & 1,178 & 5.3 \\
\hline 2001 & 59 & 2.9 & 25.4 & 1,255 & 4.7 \\
\hline 2002 & 66 & 3.2 & 28.6 & 1,348 & 4.9 \\
\hline 2003 & 62 & 3.0 & 31.6 & 1,453 & 4.3 \\
\hline 2004 & 78 & 3.8 & 35.4 & 1,562 & 5.0 \\
\hline 2005 & 85 & 4.1 & 39.6 & 1,695 & 5.0 \\
\hline 2006 & 108 & 5.3 & 44.8 & 1,792 & 6.0 \\
\hline 2007 & 95 & 4.6 & 49.5 & 1,917 & 5.0 \\
\hline 2008 & 101 & 4.9 & 54.4 & 2,048 & 4.9 \\
\hline 2009 & 112 & 5.5 & 59.8 & 2,184 & 5.1 \\
\hline 2010 & 103 & 5.0 & 64.8 & 2,299 & 4.5 \\
\hline 2011 & 102 & 5.0 & 69.8 & 2,419 & 4.2 \\
\hline 2012 & 133 & 6.5 & 76.3 & 2,546 & 5.2 \\
\hline 2013 & 120 & 5.8 & 82.1 & 2,663 & 4.5 \\
\hline 2014 & 129 & 6.3 & 88.4 & 2,757 & 4.7 \\
\hline 2015 & 118 & 5.7 & 94.2 & 2,831 & 4.2 \\
\hline 2016 & 120 & 5.8 & 100.0 & 2,881 & 4.2 \\
\hline Total & 2,054 & 100.0 & & & \\
\hline
\end{tabular}

Table 5 - Number of promotions by year. The table reports the number of promotions (from assistant professor to associate professor, and from associate professor to full professor) by year, from January 1, 1990, to December 31, 2016. 


\begin{tabular}{|c|c|c|c|}
\hline Journal Name & Abbreviation & N Articles & Finance \\
\hline Journal of Financial Economics & $J F E$ & 2,857 & 1 \\
\hline Journal of Finance & $J F$ & 2,603 & 1 \\
\hline Review of Financial Studies & $R F S$ & 1,846 & 1 \\
\hline Journal of Banking and Finance & $J B F$ & 1,595 & 1 \\
\hline Journal of Financial and Quantitative Analysis & $J F Q A$ & 1,219 & 1 \\
\hline Journal of Corporate Finance & $J C F$ & 831 & 1 \\
\hline American Economic Review & $A E R$ & 530 & 0 \\
\hline Journal of Financial Research & $J F R$ & 509 & 1 \\
\hline Financial Review & $F R$ & 502 & 1 \\
\hline Journal of Futures Markets & $J F M$ & 456 & 1 \\
\hline Management Science & $M S$ & 440 & 0 \\
\hline Financial Management & $F M$ & 436 & 1 \\
\hline Journal of Empirical Finance & $J E F$ & 396 & 1 \\
\hline Review of Finance & $R F$ & 382 & 1 \\
\hline Economics Letters & $E L$ & 364 & 0 \\
\hline Journal of International Money and Finance & $J I M F$ & 370 & 1 \\
\hline Review of Quantitative Finance and Accounting & $R Q F A$ & 353 & 1 \\
\hline Financial Analysts Journal & FAJ & 352 & 1 \\
\hline Journal of Monetary Economics & $J M E$ & 355 & 0 \\
\hline Journal of Econometrics & $J E$ & 315 & 0 \\
\hline Journal of Financial Intermediation & $J F I$ & 326 & 1 \\
\hline Journal of Real Estate Finance and Economics & JREFE & 323 & 1 \\
\hline Real Estate Economics & $R E E$ & 328 & 0 \\
\hline Journal of Business Finance and Accounting & $J B F A$ & 313 & 0 \\
\hline Journal of Financial Markets & $J F M K T$ & 289 & 1 \\
\hline Journal of Portfolio Management & $J P M$ & 268 & 1 \\
\hline Journal of Economic Dynamics and Control & $J E D C$ & 273 & 0 \\
\hline Applied Financial Economics & $A F E$ & 272 & 1 \\
\hline Pacific Basin Finance Journal & $P B F J$ & 268 & 1 \\
\hline Journal of Business & $J B$ & 259 & 1 \\
\hline International Review of Financial Analysis & $I R F A$ & 265 & 1 \\
\hline European Financial Management & $E F M$ & 248 & 1 \\
\hline Journal of Economic Theory & $J E T$ & 252 & 0 \\
\hline Journal of Derivatives & $J D$ & 200 & 1 \\
\hline Journal of Risk and Insurance & $J R I$ & 178 & 1 \\
\hline Applied Economics & $A E$ & 185 & 0 \\
\hline Journal of Money, Credit and Banking & $J M C B$ & 188 & 1 \\
\hline Quarterly Review of Economics and Finance & $Q R E F$ & 187 & 0 \\
\hline Journal of Business and Economic Statistics & $J B E S$ & 184 & 0 \\
\hline Managerial Finance & $M A N F$ & 168 & 1 \\
\hline Journal of Economics and Business & $J E B$ & 181 & 0 \\
\hline Journal of International Financial Markets, Institutions and Money & JIFMIM & 185 & 1 \\
\hline Journal of Financial Services Research & $J F S R$ & 185 & 1 \\
\hline Quarterly Journal of Economics & QJE & 174 & 0 \\
\hline Finance Research Letters & $F R L$ & 165 & 1 \\
\hline Applied Economics Letters & $A E L$ & 152 & 0 \\
\hline Quantitative Finance & $Q F$ & 159 & 1 \\
\hline International Review of Economics and Finance & IREF & 157 & 0 \\
\hline European Journal of Finance & $E J F$ & 156 & 1 \\
\hline Journal of Accounting and Economics & $J A E$ & 156 & 0 \\
\hline
\end{tabular}

Table 6 - Journals ranked by number of publications. The table reports the journals and the corresponding number of articles published by the 2,910 scholars in our sample, as of December 31,2017 . We only report the first 50 journals by the number of published articles in these outlets. Finance is a dummy variable which takes 1 if the journal belongs to the "finance" field, as of the ABS journal ranking 2015, and 0 otherwise (the Journal of Business is classified as a finance journal, despite not appearing in the ABS journal ranking). 


\begin{tabular}{|c|c|c|c|c|c|c|c|c|}
\hline \multicolumn{3}{|c|}{ 2008-2016 } & \multicolumn{3}{|c|}{ 1999-2007 } & \multicolumn{3}{|c|}{$1990-1998$} \\
\hline Journal & $\mathbf{N}$ & Mean & Journal & $\mathbf{N}$ & Mean & Journal & $\mathbf{N}$ & Mean \\
\hline$J F E$ & 563 & 0.56 & $J F$ & 354 & 0.57 & $J F$ & 199 & 0.62 \\
\hline$R F S$ & 505 & 0.51 & $J F E$ & 276 & 0.45 & $J F Q A$ & 88 & 0.27 \\
\hline$J F$ & 388 & 0.39 & $R F S$ & 205 & 0.33 & $J F E$ & 77 & 0.24 \\
\hline$J B F$ & 247 & 0.25 & $J B F$ & 114 & 0.19 & $J F R$ & 64 & 0.20 \\
\hline$J F Q A$ & 204 & 0.20 & $J F Q A$ & 112 & 0.18 & $F R$ & 55 & 0.17 \\
\hline$J C F$ & 166 & 0.17 & $J B$ & 86 & 0.14 & $J B F$ & 54 & 0.17 \\
\hline$R F$ & 76 & 0.08 & $F M$ & 52 & 0.08 & $R Q F A$ & 29 & 0.09 \\
\hline$F M$ & 75 & 0.08 & $J C F$ & 48 & 0.08 & $\widetilde{J F M}$ & 26 & 0.08 \\
\hline$J F M K T$ & 71 & 0.07 & $J F M$ & 47 & 0.08 & $R F S$ & 22 & 0.07 \\
\hline$J E F$ & 68 & 0.07 & $J F R$ & 44 & 0.07 & $J F I$ & 21 & 0.07 \\
\hline$J I M F$ & 60 & 0.06 & $F A J$ & 37 & 0.06 & JREFE & 16 & 0.05 \\
\hline$E F M$ & 54 & 0.05 & JREFE & 37 & 0.06 & $F M$ & 14 & 0.04 \\
\hline$J F I$ & 53 & 0.05 & $F R$ & 36 & 0.06 & $J I M F$ & 11 & 0.03 \\
\hline$I R F A$ & 47 & 0.05 & $J F M K T$ & 34 & 0.06 & $P B F J$ & 11 & 0.03 \\
\hline$J F R$ & 44 & 0.04 & $J E F$ & 33 & 0.05 & $J C F$ & 10 & 0.03 \\
\hline$F A J$ & 42 & 0.04 & $R Q F A$ & 31 & 0.05 & $J E F$ & 10 & 0.03 \\
\hline$R Q F A$ & 37 & 0.04 & $A F E$ & 31 & 0.05 & $J F S R$ & 10 & 0.03 \\
\hline$A F E$ & 37 & 0.04 & $J I M F$ & 27 & 0.04 & $F A J$ & 7 & 0.02 \\
\hline$F R$ & 35 & 0.04 & $J F I$ & 27 & 0.04 & $A F E$ & 6 & 0.02 \\
\hline$J F M$ & 33 & 0.03 & $J P M$ & 24 & 0.04 & $J P M$ & 5 & 0.02 \\
\hline
\end{tabular}

Table 7 - Number of publications in finance journals around the promotion by time. The table reports the number of publications in the first 20 finance journals (i.e., belonging to the "finance" field, as of the ABS journal ranking 2015) in the $[-4,+1]$ time window surrounding a promotion (both from assistant professor to associate professor, and from associate professor to full professor), broken up by time period of equal size (2008 to 2016, 1998 to 2007, and 1990 to 1997). Only the first 20 journals by number of articles are reported. 


\begin{tabular}{|c|c|c|c|c|}
\hline Journal & $\begin{array}{c}\text { Rank (2008-2016), } \\
\text { table } 7\end{array}$ & $\begin{array}{l}\text { Currie and Pandher } \\
\text { (2011), table } 5\end{array}$ & $\begin{array}{c}\text { Chan et al. (2013), } \\
\text { tables } 1,4 \text {, and } 5\end{array}$ & $\begin{array}{l}\text { Currie and Pandher } \\
\text { (2020), table } 7\end{array}$ \\
\hline$J F E$ & 1 & $\mathrm{~A}+$ & 2 & $\mathrm{~A}+$ \\
\hline$R F S$ & 2 & A+ & 3 & $\mathrm{~A}+$ \\
\hline$J F$ & 3 & A+ & 1 & A+ \\
\hline$J B F$ & 4 & $\mathrm{~A}^{-}$ & 12 & $\mathrm{~A}^{-}$ \\
\hline$J F Q A$ & 5 & A+ & 5 & $\mathrm{~A}+$ \\
\hline$\widetilde{J C F}$ & 6 & $\mathrm{~B}+$ & 8 & $\mathrm{~A}^{-}$ \\
\hline$R F$ & 7 & B & . & A \\
\hline$F M$ & 8 & $\mathrm{~B}+$ & 10 & $\mathrm{~B}+$ \\
\hline$J F M K T$ & 9 & $\mathrm{~B}+$ & 7 & $\mathrm{~B}+$ \\
\hline$J E F$ & 10 & $\mathrm{~B}+$ & 11 & $\mathrm{~B}+$ \\
\hline JIMF & 11 & $\mathrm{~B}+$ & 15 & B \\
\hline$E F M$ & 12 & $\mathrm{~B}^{-}$ & 9 & B \\
\hline$J F I$ & 13 & $\mathrm{~A}^{-}$ & 6 & $\mathrm{~A}^{-}$ \\
\hline IRFA & 14 & $\mathrm{C}$ & . & $\mathrm{B}$ \\
\hline$J F R$ & 15 & B & 17 & B \\
\hline$F A J$ & 16 & B & 16 & . \\
\hline$R Q F A$ & 17 & $\mathrm{C}+$ & 21 & B \\
\hline$\widetilde{A F E}$ & 18 & $\mathrm{C}$ & . & . \\
\hline$F R$ & 19 & B & 18 & B \\
\hline$J F M$ & 20 & B & 20 & B \\
\hline
\end{tabular}

Table 8 - Ranking comparison. The table compares the finance journal ranking from this paper, using the promotions in the period 2008 to 2016, with the ranking proposed in Currie and Pandher (2011), Chan, Chang, and Chang (2013), and Currie and Pandher (2020). Chan et al. (2013) offer three methods to establish the journal ranking. In this table, we report the ranking obtained as the average of the three methods. 


\begin{tabular}{|c|c|c|c|c|c|}
\hline \multicolumn{2}{|c|}{ 2008-2016 } & \multicolumn{2}{|c|}{ 1999-2007 } & \multicolumn{2}{|c|}{ 1990-1998 } \\
\hline Journal & $\mathrm{N}, \%$ & Journal & $\mathrm{N}, \%$ & Journal & $\mathbf{N}$ \\
\hline$R F S$ & 41.5 & $R F S$ & 35.9 & $J F Q A$ & 19.3 \\
\hline$J F E$ & 36.7 & $J F$ & 30.6 & $J F$ & 17.4 \\
\hline$J F$ & 36.2 & $J F E$ & 29.2 & $J F I$ & 17.4 \\
\hline$J F Q A$ & 27.3 & $J F Q A$ & 25.2 & $R F S$ & 15.8 \\
\hline$J F M K T$ & 21.5 & $J B$ & 20.2 & $J F R$ & 13.0 \\
\hline$F M$ & 17.1 & $J F M K T$ & 18.5 & $F M$ & 12.4 \\
\hline$J C F$ & 15.2 & $F M$ & 16.9 & $J C F$ & 12.3 \\
\hline$R F$ & 14.6 & $J C F$ & 13.2 & $J F E$ & 12.1 \\
\hline$J F I$ & 14.3 & $J F I$ & 10.8 & $R Q F A$ & 10.7 \\
\hline$J F R$ & 13.1 & $J F R$ & 10.0 & $J E F$ & 9.4 \\
\hline$E F M$ & 11.2 & $J E F$ & 9.2 & $F R$ & 7.7 \\
\hline$F R$ & 8.9 & $F R$ & 7.7 & $P B F J$ & 6.5 \\
\hline$J E F$ & 8.7 & JREFE & 6.9 & $J B F$ & 6.0 \\
\hline$J B F$ & 7.6 & $J B F$ & 6.9 & JREFE & 4.3 \\
\hline$F A J$ & 6.1 & $J F M$ & 6.6 & $J F M$ & 3.7 \\
\hline$R Q F A$ & 5.0 & $R Q F A$ & 6.0 & $F A J$ & 3.5 \\
\hline IRFA & 4.8 & $F A J$ & 5.6 & $J F S R$ & 3.2 \\
\hline$J I M F$ & 4.5 & $J P M$ & 3.6 & $J P M$ & 2.6 \\
\hline$J F M$ & 4.3 & $J I M F$ & 3.6 & $J I M F$ & 1.9 \\
\hline$A F E$ & 2.5 & $A F E$ & 2.6 & $A F E$ & 1.3 \\
\hline
\end{tabular}

Table 9 - Percentage of publications in finance journals around the promotion by time. The table reports the number of publications in the first 20 finance journals (i.e., belonging to the "finance" field, as of the ABS journal ranking 2015) in the $[-4$, +1 ] time window surrounding a promotion (both from assistant professor to associate professor, and from associate professor to full professor), standardized by the total number of articles published by the journal, broken up by periods of equal length (2008 to 2016,1998 to 2007 , and 1990 to 1997 ). 


\begin{tabular}{|c|c|c|c|c|c|c|c|c|}
\hline \multicolumn{3}{|c|}{ Group $1(\mathrm{~N}=25)$} & \multicolumn{3}{|c|}{ Group $2(\mathbf{N}=87)$} & \multicolumn{3}{|c|}{ Group $3(N=275)$} \\
\hline Journal & $\mathbf{N}$ & Mean & Journal & $\mathbf{N}$ & Mean & Journal & $\mathbf{N}$ & Mean \\
\hline$J F$ & 423 & 1.13 & $J F E$ & 368 & 0.61 & $J B F$ & 278 & 0.29 \\
\hline$J F E$ & 354 & 0.94 & $J F$ & 340 & 0.56 & $J F E$ & 194 & 0.20 \\
\hline$R F S$ & 285 & 0.76 & $R F S$ & 315 & 0.52 & $J F$ & 178 & 0.19 \\
\hline$J F Q A$ & 55 & 0.15 & $J F Q A$ & 187 & 0.31 & $J F Q A$ & 162 & 0.17 \\
\hline$R F$ & 23 & 0.06 & $J B F$ & 129 & 0.21 & $J C F$ & 143 & 0.15 \\
\hline$J F I$ & 19 & 0.05 & $J C F$ & 75 & 0.12 & $R F S$ & 132 & 0.14 \\
\hline$J B$ & 19 & 0.05 & $J B$ & 55 & 0.09 & $J F R$ & 126 & 0.13 \\
\hline$F M$ & 17 & 0.05 & $F M$ & 40 & 0.07 & $F R$ & 108 & 0.11 \\
\hline$F A J$ & 17 & 0.05 & $J E F$ & 37 & 0.06 & $F M$ & 84 & 0.09 \\
\hline$J F M K T$ & 16 & 0.04 & $R F$ & 36 & 0.06 & $J F M$ & 76 & 0.08 \\
\hline$J E F$ & 15 & 0.04 & $J I M F$ & 34 & 0.06 & $R Q F A$ & 74 & 0.08 \\
\hline$J I M F$ & 11 & 0.03 & $J F I$ & 34 & 0.06 & $A F E$ & 64 & 0.07 \\
\hline$J B F$ & 8 & 0.02 & $F A J$ & 29 & 0.05 & $J F M K T$ & 61 & 0.06 \\
\hline JREFE & 8 & 0.02 & $J F M K T$ & 29 & 0.05 & $J E F$ & 59 & 0.06 \\
\hline$J P M$ & 8 & 0.02 & $J F M$ & 26 & 0.04 & IRFA & 58 & 0.06 \\
\hline$J C F$ & 6 & 0.02 & $J F R$ & 22 & 0.04 & JIMF & 53 & 0.06 \\
\hline$P B F J$ & 6 & 0.02 & $R Q F A$ & 22 & 0.04 & $J F I$ & 48 & 0.05 \\
\hline$F R L$ & 5 & 0.01 & JREFE & 22 & 0.04 & $E F M$ & 46 & 0.05 \\
\hline$J F R$ & 4 & 0.01 & $E F M$ & 22 & 0.04 & JREFE & 44 & 0.05 \\
\hline$J F M$ & 4 & 0.01 & $P B F J$ & 20 & 0.03 & $F A J$ & 40 & 0.04 \\
\hline
\end{tabular}

Table 10 - Number of publications in finance journals around the promotion by institution quality. The table reports the number of publications in the first 20 finance journals (i.e., belonging to the "finance" field, as of the ABS journal ranking 2015), in the $[-4,+1]$ time window surrounding a promotion (both from assistant professor to associate professor, and from associate professor to full professor), broken up by the quality of the institution (group 1, group 2, group 3). Groups are formed as follows: the first 25 schools in the Arizona State University ranking (number of articles in top-three finance journals greater than 55 in the 2006-2015 decade) are classified as "group 1," the following 87 schools (number of articles in top-three finance journals between 10 and 54) are classified as "group 2," while the remaining 275 schools (number of articles in top-three finance journals between 1 and 9) are classified as "group 3." 


\begin{tabular}{|c|c|c|c|c|c|c|c|c|}
\hline \multicolumn{3}{|c|}{ North America } & \multicolumn{3}{|c|}{ Europe } & \multicolumn{3}{|c|}{ Asia-Australia/Oceania-South America } \\
\hline Journal & $\mathbf{N}$ & Mean & Journal & $\mathbf{N}$ & Mean & Journal & $\mathbf{N}$ & Mean \\
\hline$J F$ & 775 & 0.61 & $J B F$ & 150 & 0.34 & $J F E$ & 66 & 0.29 \\
\hline$J F E$ & 740 & 0.59 & $R F S$ & 128 & 0.29 & $J B F$ & 64 & 0.28 \\
\hline$R F S$ & 550 & 0.44 & $J F$ & 122 & 0.27 & $R F S$ & 54 & 0.24 \\
\hline$J F Q A$ & 309 & 0.24 & $J F E$ & 110 & 0.25 & $J F Q A$ & 52 & 0.23 \\
\hline$J B F$ & 201 & 0.16 & $J I M F$ & 48 & 0.11 & $J F$ & 44 & 0.20 \\
\hline$J C F$ & 144 & 0.11 & $J C F$ & 46 & 0.10 & $J C F$ & 34 & 0.15 \\
\hline$F M$ & 125 & 0.10 & $J F Q A$ & 43 & 0.10 & $P B F J$ & 34 & 0.15 \\
\hline$J F R$ & 123 & 0.10 & $A F E$ & 40 & 0.09 & $J F R$ & 20 & 0.09 \\
\hline$F R$ & 113 & 0.09 & $E F M$ & 40 & 0.09 & $J F M$ & 14 & 0.06 \\
\hline$R Q F A$ & 82 & 0.06 & $I R F A$ & 37 & 0.08 & $J E F$ & 14 & 0.06 \\
\hline$J B$ & 80 & 0.06 & $J E F$ & 28 & 0.06 & $R F$ & 14 & 0.06 \\
\hline$J F M K T$ & 77 & 0.06 & $J F M$ & 27 & 0.06 & $J F M K T$ & 14 & 0.06 \\
\hline$J F I$ & 71 & 0.06 & $E J F$ & 27 & 0.06 & $F R$ & 11 & 0.05 \\
\hline$F A J$ & 70 & 0.06 & $R F$ & 26 & 0.06 & $R Q F A$ & 11 & 0.05 \\
\hline$J E F$ & 69 & 0.05 & $J F I$ & 20 & 0.04 & $J F I$ & 10 & 0.04 \\
\hline$J F M$ & 65 & 0.05 & $J F M K T$ & 15 & 0.03 & $J B$ & 10 & 0.04 \\
\hline JREFE & 64 & 0.05 & $J M C B$ & 15 & 0.03 & $I R F A$ & 10 & 0.04 \\
\hline$R F$ & 51 & 0.04 & $J F S R$ & 12 & 0.03 & $E F M$ & 10 & 0.04 \\
\hline$J I M F$ & 42 & 0.03 & $F R L$ & 12 & 0.03 & JIFMIM & 9 & 0.04 \\
\hline$J P M$ & 41 & 0.03 & $Q F$ & 12 & 0.03 & $F M$ & 8 & 0.04 \\
\hline
\end{tabular}

Table 11 - Number of publications in finance journals around the promotion by location of the institution (North America, Europe, AsiaAustralia/Oceania-South America). The table reports the number of publications in the first 20 finance journals (i.e., belonging to the "finance" field, as of the ABS journal ranking 2015), standardised by the number of co-authors, in the $[-4,+1]$ time window surrounding a promotion (both from assistant professor to associate professor, and from associate professor to full professor), broken up by the location of the institution (North America, Europe, Asia-Australia/Oceania-South America). 